\title{
Clarification of Ki67 Expression in Association with the Histological Picture of Endometrium in Cases with Abnormal Uterine Bleeding in Nineveh Province
}

\author{
Sura Atallah Mahmoud Al-Nuaimy*, Luma Ibrahim Khalel Al-Allaf** , Zahraa Marwan Al-Omar** \\ ${ }^{*}$ Postgraduate Student, Department of Anatomy, College of Medicine , University of Mosul , \\ ${ }^{\star *}$ Department of Anatomy, College of Medicine, University of Mosul, ${ }^{\star \star \star}$ Department of Pathology, \\ College of Medicine, University of Mosul, Mosul, Iraq \\ Correspondence: sura.hmp28@student.uomosul.edu.iq
}

(Ann Coll Med Mosul 2021; 43 (2):176-190).

Received: $8^{\text {th }}$ Augu. 2021; Accepted: $26^{\text {th }}$ Sept. 2021.

\begin{abstract}
Background: Among the frequent daily challenges in the practice of gynecology are abnormal uterine bleeding (AUB) beside the distinction of fundamental endometrial lesions that stand behind it .Ki67 is among the excellent markers as the higher proliferation rate is one of the features of cancer cells.

Aim: This study aims to clarify the expression of Ki67 in the endometrium of women suffering from abnormal uterine bleeding in Nineveh Province and to correlate its expression with the histological picture.

Subjects, Materials, and Methods: This is a case series study that was enrolled analysis of data (retrospectively and prospectively) of 51 females who were presented with history of abnormal uterine bleeding and they were underwent an elective D\&C and or hysterectomy after admission in several Hospitals, in Nineveh Province, Northern Iraq from $1^{\text {st }}$ January, 2020 to $30^{\text {th }}$ December, 2020. The selected paraffin blocks $(n-=51)$ were cut into 3-4 micrometers thick sections and mounted on poly-L-lysine glass slides for immunohistochemical staining with using of positive and negative control sections at Unit of Immunohistochemistry in Vin Hospital -Duhok-North of Iraq. Staining was performe using the optimized protocol recommended by the International Ki67 in Breast Cancer Working Group together with Dako Autostainer according to manufacturer instructions.

Results: This work revealed that $23(45 \%)$ out of 51 cases were aged $>50$ years. The highest mean of percentage of Ki67expression was in sections of proliferative endometrium. In fact, sections of 3/7 of cases which were exhibited a percentage of Ki67 expression from $76 \%$ to $100 \%$ aged $>50$ years, while sections of $3 / 7$ of cases of menopause women showed percentage of Ki67 expression from 26\% to $75 \%$. Further, 12 cases out of 17 showed an intensity of staining score of 2 were aged $<50$ years, while 3 out of 5 cases (which revealed an intensity of 3 ) were aged $<50$ years. Five cases out of 17 which showed an intensity of staining score of 2 were aged $>50$ years, while 2 out of 5 cases which exhibited an intensity score of 3 were aged $>50$ years. The current study showed that $11 / 16$ cases of benign conditions presented with percentage of Ki67 expression of less than 25\%,while 14/15 cases of endometrial hyperplasia presented with Ki67 expression of $<25 \%$. In contrary, 8 cases out of 20 of cases of endometrial adenocarcinoma showed Ki67 expression of $>25 \%$. Further, the intensity of Ki67 immunostaining of more than 2 was shown in 4 cases of endometrial adenocarcinoma. Regarding cases of endometrial hyperplasia, the current work revealed that 7 cases $(46 \%)$ out of 15 cases were aged more than 50 years. About 4 cases $(26 \%)$ of them are of atypical type with no significant differences between the percentage and intensity of Ki67 expression in cases of endometrial hyperplasia. In fact, 15 cases $(75 \%)$ of endometrial adenocarcinoma were aged more than 50 years. Four $(20 \%)$ of them were of grade 3 , while six cases $(30 \%)$ of them were of grade 2 . According to the grade of endometrial adenocarcinoma, sections of 2 out of 5 cases of grade one (well differentiation) endometrial adenocarcinoma showed the percentage of Ki67 expression of more than $15 \%$, while 5 out of 10 cases of grade 2 (Moderately differentiation) endometrial adenocarcinoma showed the percentage of Ki67 expression of more than 15\%. Finally, 3 out of 5 cases of grade 3 (poorly differentiation) endometrial adenocarcinoma showed the percentage of Ki67 expression of more than 15\%. About 5 cases out of 16 with Ki67 expression of more than 25\%.Finally, 8 cases out of 20 cases of endometrial adenocarcinoma showed the Ki67 expression of more than $25 \%$.

Conclusion: Analysis of immunohistochemical expression of Ki67 in sections of women presented with AUB revealed that there is a relation with the age of patients. A significant association between expression of the Ki67 and poor tumor characteristics was conclude. Significant differences was shown between the expression of the Ki67 in sections of proliferative phase and those of endometrial hyperplasia ,while significant differences was found between the expression of the Ki67 in sections of endometrial hyperplasia
\end{abstract}


and those of endometrial carcinoma. Using of Ki67 as diagnostic and prognostic tool in endometrial carcinoma may be conclude.

Keywords: Ki67 expression, histology, endometrium, abnormal uterine bleeding, endometrial carcinoma.

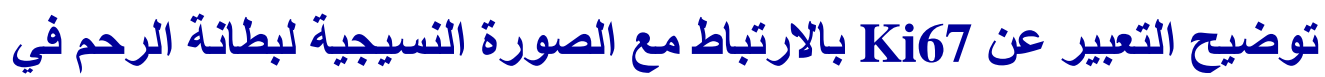

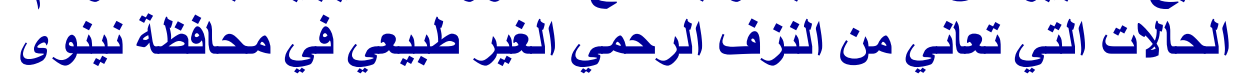

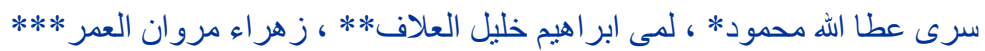

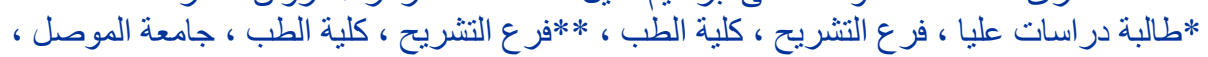

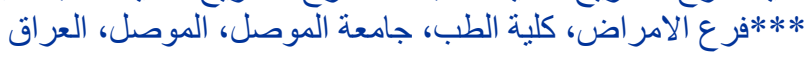

الخلاصة

الخلفية: من ضمن التحديات الكثبرة اليومية في الجانب العملي للنسائية هو النزف الرحاف الرحمي الغير منتظم بجانب تحديد افات بطانة

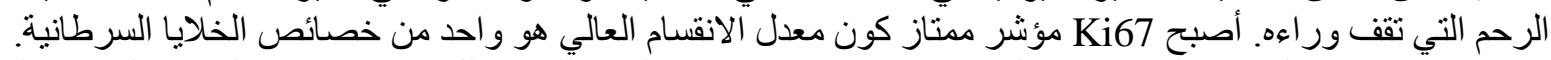

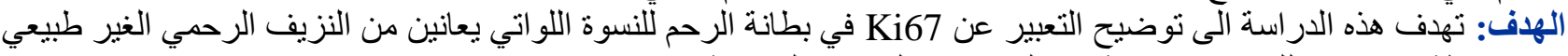

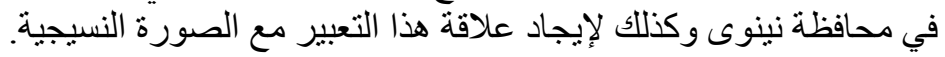

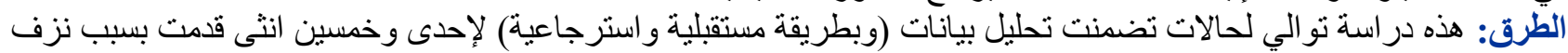

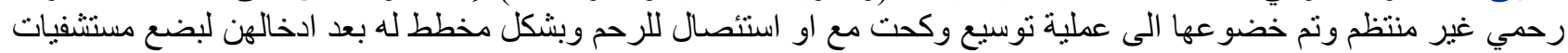

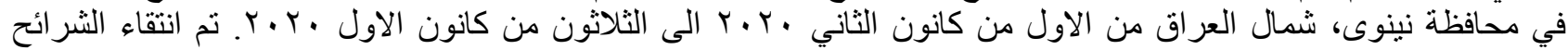

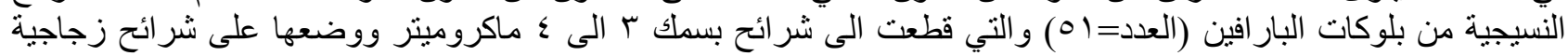

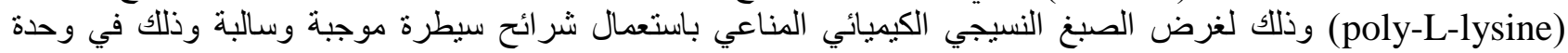

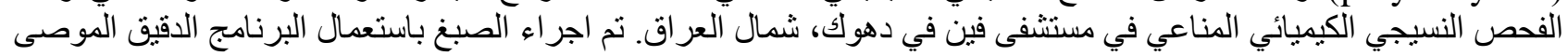

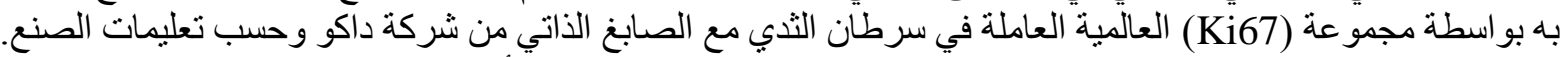

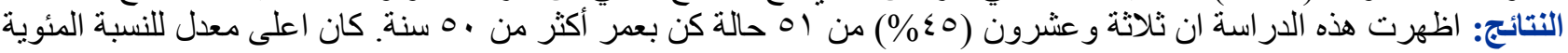

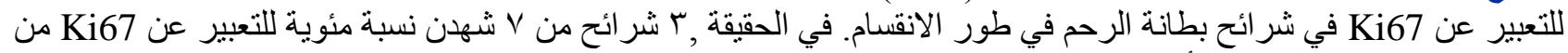

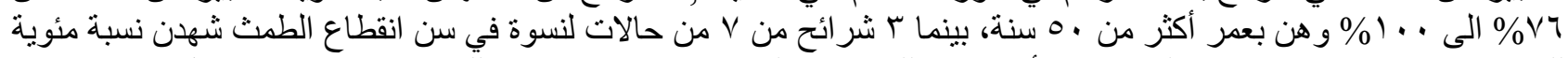

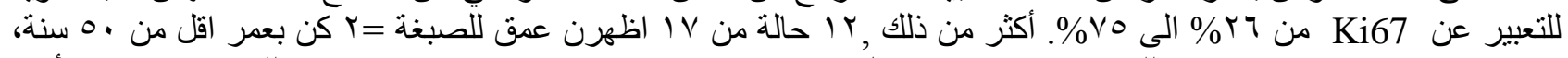

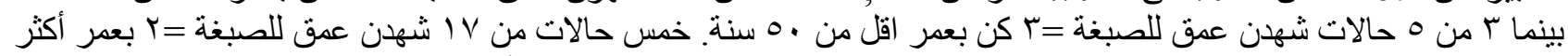

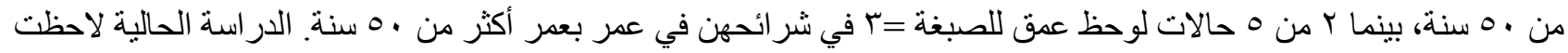

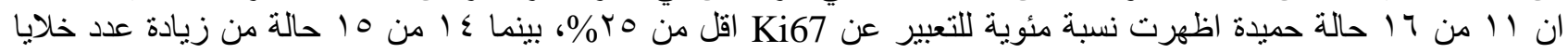

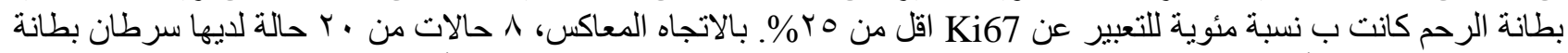

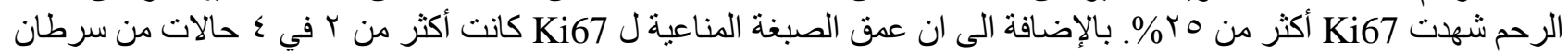

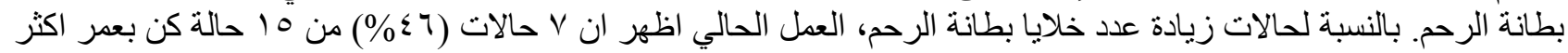

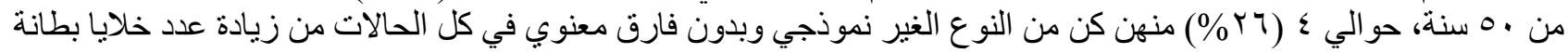

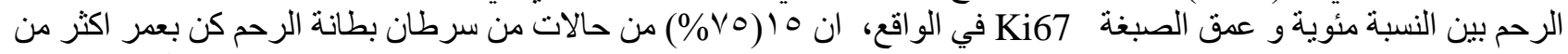

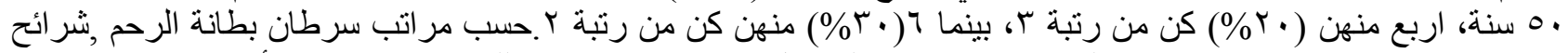

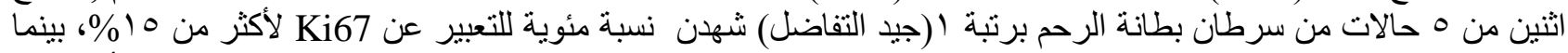

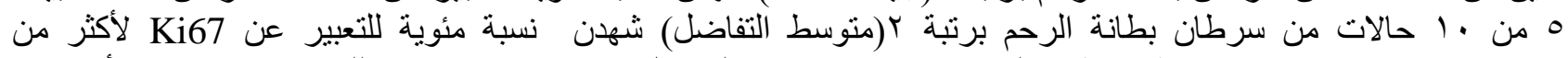

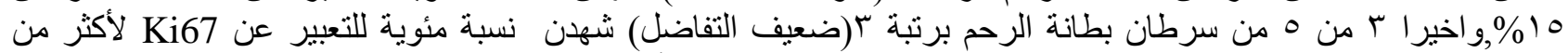

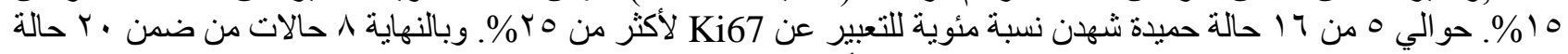

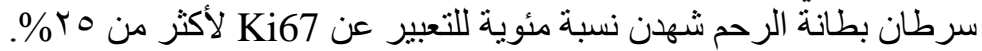

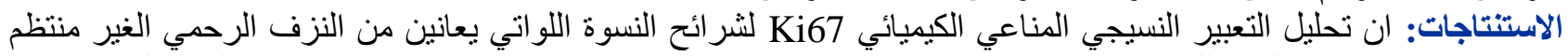

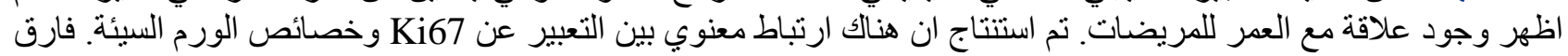

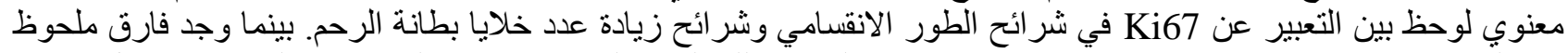

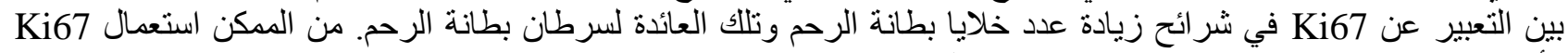

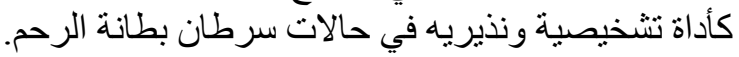


الكلمات المفتاحية: التعبير عن Ki67، علم الانسجة، بطانة الرحم، نزيف رحمي غير منتظم، سرطان بطانة الرحم.

\section{INTRODUCTION}

mong the frequent daily challenges in the practice of gynecology are abnormal uterine bleeding $(A \cup B)$ beside the distinction of fundamental endometrial lesions that stand behind it. Benign conditions represent the most common cause for AUB including alteration in steroid hormones' levels, leiomyoma (fibroids), and different types of endometrial disorders ${ }^{1}$. When the patients have the symptom, the detection of the exact cause and the defining whether there is any association with the malignancy (inside the uterus) are the priorities, in addition to evaluate the choice for the suitable management ${ }^{2}$.

Further, there is a substantial increasing in the risk of endometrial cancer in postmenopausal women, as any AUB could be the first sign of endometrial malignancy ${ }^{3}$. On the other hand, endometrial hyperplasia, is an the abnormal, noninvasive proliferation of the endometrial tissue resulting from excess estrogenic stimulation, is among the commonest causes of AUB that leads to endometrial carcinomas if remains untreated $^{4}$.Pathologically, endometrial hyperplasia constitutes a heterogeneous group of lesions, and represents a range of irregular morphological alterations causing a raised in gland : stroma ratio in comparison with endometrium of the proliferative phase of the cycle $e^{5,6}$.

The recent World Health Organization-WHO classification that approved by the International Society of Gynecological Pathologists classified the endometrial hyperplasia into:

1. Benign endometrial hyperplasia.

2. Atypical endometrial hyperplasia/endometrial intraepithelial neoplasia (EIN) ${ }^{4}$.

The tendency of development of endometrial hyperplasia to carcinoma depends upon the extent of abnormality in architecture, and the evidence of nuclear atypia. It is well documented that progressing of endometrial hyperplasia to endometrial cancer is raised in cases with atypia in comparison with those with without atypical hyperplasia, however the amplitude of such risk is not certain yet ${ }^{7,8}$.

The possibility of endometrial hyperplasia progression to endometrial carcinoma ranging from $1 \%$ for benign endometrial hyperplasia into $46.2 \%$ for endometrial intraepithelial neoplasia ${ }^{9}$.

Distinction between these forms of endometrial hyperplasia is essential for ideal management, and it correlated with the extent of architectural complexity beside cellular atypia. The latter represents the basic histological determining factor for prospective malignancy ${ }^{\text {to }}$.
On the other hand, another commonest histopathologic finding is an endometrial polyp, followed by proliferative and secretory endometrium respectively. It has been shown that polyp of asymptomatic women (post menopause) exhibited markedly higher proliferation (in epithelium and stroma) than inactive atrophic endometrium; however, it has lessor extent when compared to benign polyps at premenopause age and/or endometrial cancer. Benign endometrial polyps at postmenopausal age expressed less proliferative activity, indicating lower malignant potential and the resection may be not required in asymptomatic cases ${ }^{11}$.

All over the World, endometrial carcinoma is the second most common malignancy in gynecological field that is introduce itself as AUB usually in the early postmenopausal periods ${ }^{12,13}$.

The precise quantifying of endometrial cancer potential is vital for cases, which diagnosed as endometrial hyperplasia to reach a suitable shared decision concerning the optimal and appropriate clinical management protocols ${ }^{8}$.

Incidence of endometrial carcinoma is raised in premenopausal women ${ }^{14}$, and it is one of the most common pelvic gynecologic cancer in the developing societies that could develop in normal, atrophic, or hyperplastic endometria ${ }^{4,5,15}$. Many of these malignancies are discovered at an early stage, with the tumor restricted to the corpus uteri in $75 \%$ of cases with generally a favorable prognosis $^{16,17}$.

Specific microscopic criteria were used to distinct between benign endometrial hyperplasia and atypical endometrial hyperplasia via hematoxylin and eosin (H\&E) staining of endometrial sections; however, the subjective difference between the observers may be notice in such histopathologic evaluation specifically in the determination of atypical type. Therefore, the special immunohistochemical markers is necessary to confirm the diagnosis and to identify 'at risk' endometrial hyperplasia cases for malignant progression $^{15}$.

Cell proliferation pays an attention to the raised cells numbers after cellular growth and division. Van Diest et al. Reported that cellular proliferation is essentially a biological process for all living organisms as it has a contribution in the growth and conservation of tissues homeostasis ${ }^{18}$. Cellular proliferation is a well indicator of cell functions and among the principal marker for diagnosis and prognosis of malignancy ${ }^{19}$.

A non-histone -nuclear protein, known as Ki67, is generally associated with tumor cell proliferation 
and growth. Due to this fact, Ki67 becomes an excellent marker because a higher proliferation rate is one of the characteristics of cancer cells ${ }^{20}$, and it is involved in the early steps of polymerase Idependent ribosomal RNA synthesis. Ki67 plays an important role in cell proliferation, but its precise function is still unknown ${ }^{21,22}$.

The aggressiveness of malignant tumors of endometrium can be correlated with the proliferation of neoplastic cells, and this can be detected by immunohistochemical study of proliferative index (Ki67) ${ }^{23}$.

In spite of the fact of the raised frequency of endometrial cancer with a corresponding rising in in deaths from it, a noticeable lack of reports, which concerned with its treatment protocols and new prevention methods, seen. There is a scarcity of qualitatively high clinical trials evidence to advice the management of cases who had advanced endometrial cancer or even recurrence. Similarly, the strong evidence is lacking regarding the guidance of the clinical care of females who are surgically unfit or who want to spare their fertility ${ }^{22}$. This study aims to clarify the expression of Ki67 in the endometrium of women suffering from AUB in Nineveh Province and to correlate its expression with the histological picture.

\section{SUBJECTS, MATERIALS, AND METHODS}

This is a case series study that is enrolled analysis of data (retrospectively and prospectively) of 51 females who were presented with abnormal uterine bleeding (AUB) and were admitted in $\mathrm{Al}$ Batool Teaching Hospital, Al- Khansaa Teaching Hospital, Al-Salam Teaching Hospital, Al-Rabeeh Private Hospital, and Al-Zahrawy Private Hospital at Nineveh Province, Northern Iraq. These cases were underwent an elective dilatation and curettage and or hysterectomy during a period of one year from $1^{\text {st }}$ January, 2020 to $30^{\text {th }}$ December, 2020.

Inclusion criteria: Females who aged 18 years and above and presented with $A \cup B{ }^{24}$.

Exclusion criteria: Girls and married women who aged less than 18 years. Patients presenting with AUB due to pregnancy-related complications, gestational trophoblastic diseases, systemic causes, clotting disorders and coagulopathy, iatrogenic causes like intrauterine contraceptive device, cervical or vaginal pathology, cases of congenital malformations of uterus, and cases of inadequate endometrial samples ${ }^{24,25}$.

After obtaining the ethical approval of the Committee of the Medical Researches, Collage of Medicine, University of Mosul. (No: UOM/COM/MREC/20-21(44)), the tissues for histopathology (from dilatation and curettage, and or hysterectomy) were received in the Department of Pathology of the each of the mentioned hospitals and were routinely processed using paraffin embedded tissue blocks, and Hematoxylin and Eosin (H\&E) stained slides of these 51 cases were retrieved were reviewed blindly ${ }^{5}$. Patients were divided into premenopausal (18-50 years) and Postmenopausal (>50 years) groups along with categorization into different age groups ${ }^{24,25}$.

Immunohistochemistry:

At Unit of Immunohistochemistry in Vin Hospital Duhok-North of Iraq, sections were studied for Ki67 immunohistochemical expression using Ki67 as a primary antibody (Dako Laboratories-USA) and poly HRP as a secondary kit. Antigen retrieval done by using microwave in Tris-EDTA buffer at $\mathrm{pH}$ 9. Staining was performe with $D A B$ as chromogen.

The immunohistochemical work in this study done by Dako automated Autostainer Link 48, which ensures optimal staining results and offers a high slide and reagent capacity with Dako UltraVision LP detection system.

Paraffin blocks (after fixation with formalin) of each case were stored at room temperature for up to 24 hours. Three - Four- $\mu \mathrm{m}$ thick sections were cut from representative paraffin blocks using a cryostat, deparaffinized in xylene, dehydrated, and mounted onto a histological glass slide9 mounted on Dako FLEX IHC slides). Slides either stained immediately or stored at $+4{ }^{\circ} \mathrm{C}$ pending immunohistochemistry ${ }^{22}$. Then allowed to fix overnight in oven at temperature $65^{\circ} \mathrm{C}$. The immunohistochemical study was performed according to manufacturer instructions ${ }^{23,24}$.

Staining was performed using the optimized protocol recommended by the International Ki67 in Breast Cancer Working Group ${ }^{23,26-28}$.

Immunohistochemical Evaluation and Scoring:

All slides evaluated blindly for the immune staining by light microscopy using a Leitz dialux microscope (UK). The positive expression of Ki67 defined as presence of brown-yellow granules in cell nuclei or in both cell nuclei and cytomembrane. All stained nuclei counted as positive ${ }^{(22)}$. The positive and negative control slides in this study are lymph node with Burkitt's lymphoma, while the role of negative controls is to test for the specificity of an antibody involved. Therefore, no staining must be show when omitting the primary antibody 23

From all cases, positive nuclei counted manually in 100 glandular epithelial cells and repeated in 10 high-powered fields (400x) randomly selected and the total number of positive cells expressed as a percentage of 1000 . Then they graded as follows 
based on their positivity (the Ki67 labeling index) as:

1 - $25 \%$ - Grade 1, 26 - $50 \%$ - Grade 2, 51 - $75 \%$ - Grade 3, 76 to $100 \%$ - Grade $4{ }^{29}$.

For cases of endometrial carcinoma, manual scoring of Ki67 percentage were counted and recorded according to the Ki67 labeling index of $\leq$ $15 \%$, and $>15 \%$ respectively, and cases were classified as low and high proliferating. For statistical analysis, we grouped the patients according to the Ki67 labeling index to $\mathrm{Ki} 67 \leq 15 \%$ (low score) and Ki67 >15\% (high score) ${ }^{30}$.

According to Carangiu et al, the intensity of nuclear stain was recorded using the immunohistochemical score as 1, 2, and $3^{28,31}$.

\section{Statistical analysis:}

The association between Ki67 and variable categories was assessed using Chi-square test and Fisher Exact test when indicated. Regarding statistical analyses, the $P$ value considered statistically significant if its $<0.05^{23}$.

\section{RESULTS}

Wide spectrum of microscopic findings selected in this work. The cases of this study are ranging from proliferative phase, secretory phase, and hyperplasia to carcinoma. (Figures 1-10) and Table1.

There were 23(45\%) surgical specimens and $28(55 \%)$ biopsies of endometrium. (Figure 11).

The microscopic findings of the endometrium in 51 cases presented with AUB in the current study using hematoxylin and eosin stains shown in Table1.

The distribution of 51 cases, which presented with AUB according to the age, shown in Table 2. In fact, $23(45 \%)$ out of 51 cases were aged more than 50 years. Table 2 .

The percentage and intensity of Ki67 expression in different endometrial lesions shown in Tables 3, and 4 respectively.

On the other hand, the percentage and intensity of Ki67 expression in different age groups shown in Tables 5 and 6 respectively.

In fact, sections of $3 / 7$ cases which were exhibited percentage of Ki67 expression from 76\% to $100 \%$ were aged more than 50 years (post menopause), while sections of 3 cases of menopause women showed percentage of Ki67 expression from $26 \%$ to $75 \%$, Table 5 .

Further, 12 cases out of 17 showed an intensity of staining score of 2 were aged less than 50 years, while 3 out of 5 cases revealed an intensity of 3 in age less than 50 years. On the other hand, 5 cases out of 17 showed an intensity of staining score of 2 were aged more than 50 years, while 2 out of 5 cases revealed an intensity score of 3 were aged more than 50 years. Table 6 .
The mean percentage of Ki67 expression and mean of Intensity among different lesions of endometrium in cases of AUB shown in Table 7.

To identify the expressions of Ki67 between different tissues of endometrium in cases with AUB showed the mean percentage of Ki67 expression in sections of cases of benign, hyperplastic and of endometrial adenocarcinoma. Table 7.

The highest mean of percentage of Ki67 expression was in sections of proliferative endometrium. Table 7.

On the other hand, the current study showed that $11 / 16$ cases of benign conditions presented with percentage of Ki67 expression of less than 25\%. Table 8, while 14/15 cases of hyperplasia presented with Ki67 expression of less than 25\%. Table 8.

In contrary, 8 cases out of 20 of cases of endometrial adenocarcinoma showed Ki67 expression of more than $25 \%$. Table 8.

About 5 cases out of 16 with Ki67 expression of more than $25 \%$, while just one case exhibited features of Ki67 expression of more than $25 \%$. Finally, 8 cases out of 20 cases of endometrial adenocarcinoma showed the Ki67 expression of more than $25 \%$. Table 8.

Regarding cases of endometrial hyperplasia, the current work revealed that 7 cases $(46 \%)$ out of 15 cases were aged more than 50 years. About 4 cases $(26 \%)$ of them are of atypical type. with no significant differences between the percentage and intensity of Ki67 expression in cases of endometrial hyperplasia. Table 9.

According to the method of Gharib et al in $2020^{(30)}$, the sections of endometrial adenocarcinoma were further analyzed. Tables 10 and 11.

Relation between the percentage and intensity of Ki67 expression with age of patients in cases of endometrial adenocarcinoma shown in Table 10.

The intensity of Ki67 immunostaining score of 2 was show in 4 cases were aged more than 50 years in cases of endometrial adenocarcinoma. Table 10.

According to the grade of endometrial adenocarcinoma, sections of 2 out of 5 cases of grade one (well differentiation) endometrial adenocarcinoma showed the percentage of Ki67 expression of more than $15 \%$, while 5 out of 10 cases of grade 2 (Moderately differentiation) endometrial adenocarcinoma showed the percentage of Ki67 expression of more than 15\%. Finally, 3 out of 5 cases of grade 3 (poorly differentiation) endometrial adenocarcinoma showed the percentage of Ki67 expression of more than 15\%. (Figures 8, 9, 10) and Table 11. 


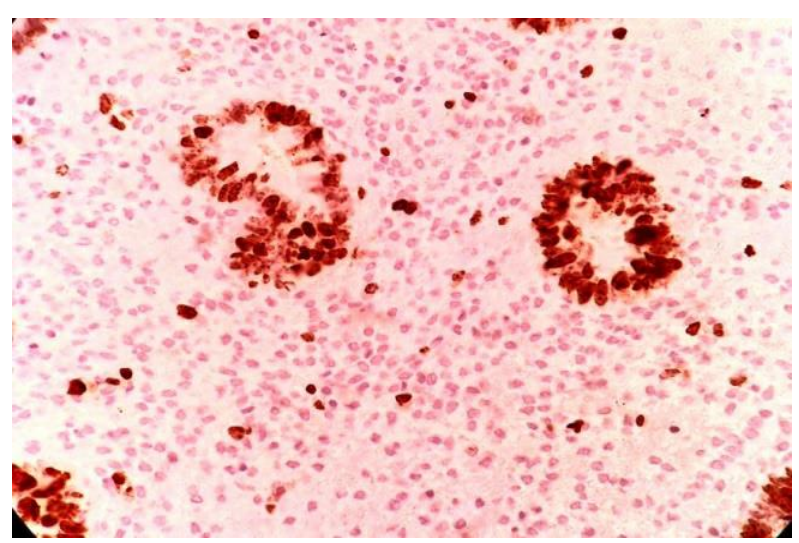

(1)

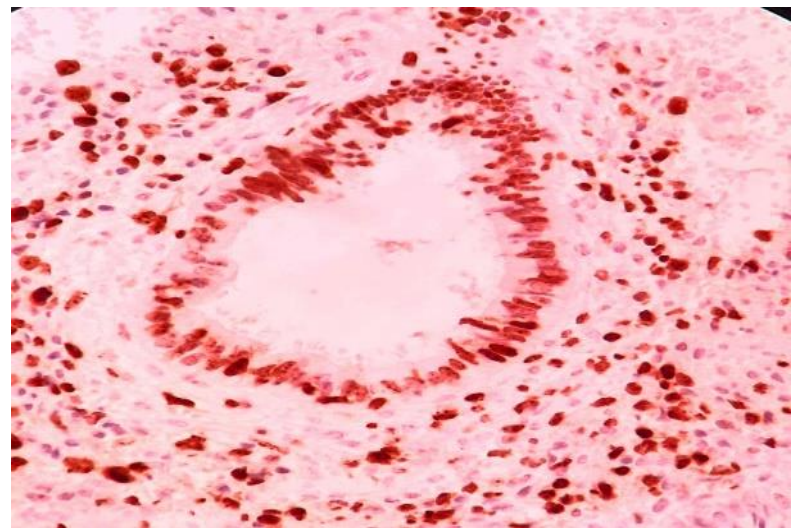

(2)

Figure 1. A photomicrograph of a histological section of the endometrial layer of a woman with AUB shows positive Ki67 expression in proliferative phase endometrium (Ki67 expression=80\%, intensity=3) (Ki67 IHC, 400x).

Figure 2. A photomicrograph of histological section of endometrial layer of women with AUB show positive $\mathrm{Ki} 67$ in secretory phase. (Ki67 expression $=80 \%$, intensity $=2)(\mathrm{Ki} 67 \mathrm{IHC}, 400 \mathrm{x})$.

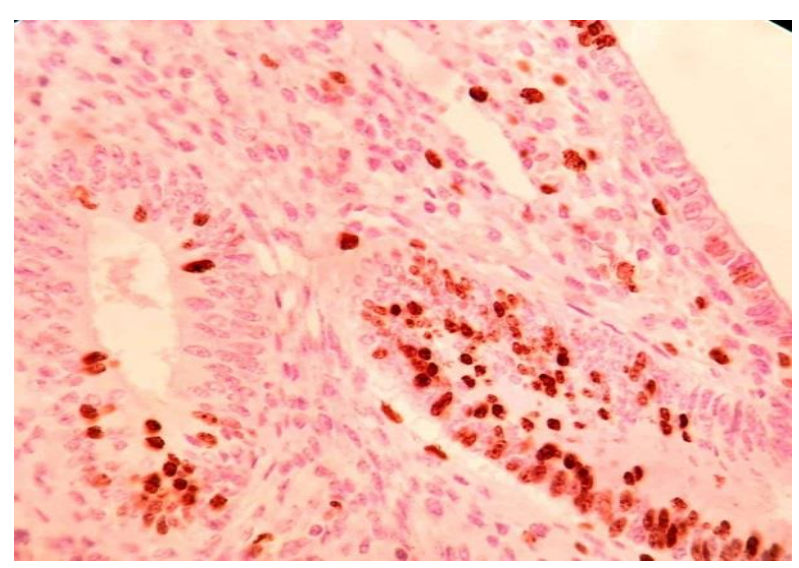

(3)

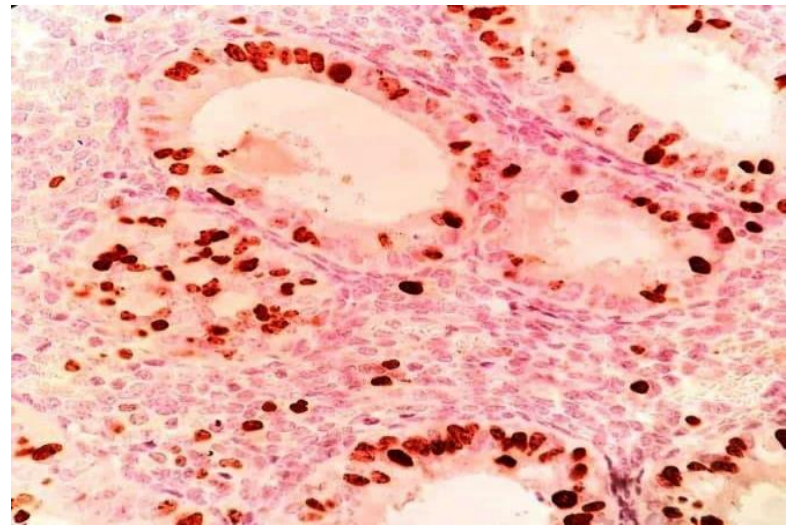

(4)

Figure 3. A photomicrograph of histological section of endometrial layer of women with AUB show positive Ki67 in endometrial hyperplasia without atypia. (Ki67 expression $=50 \%$, intensity=2) (Ki67 IHC, 400x).

Figure 4. A photomicrograph of histological section of endometrial layer of women with AUB show positive Ki67 in atypical endometrial hyperplasia. (Ki67 expression=25\%, intensity=2) (Ki67 IHC, 400x).

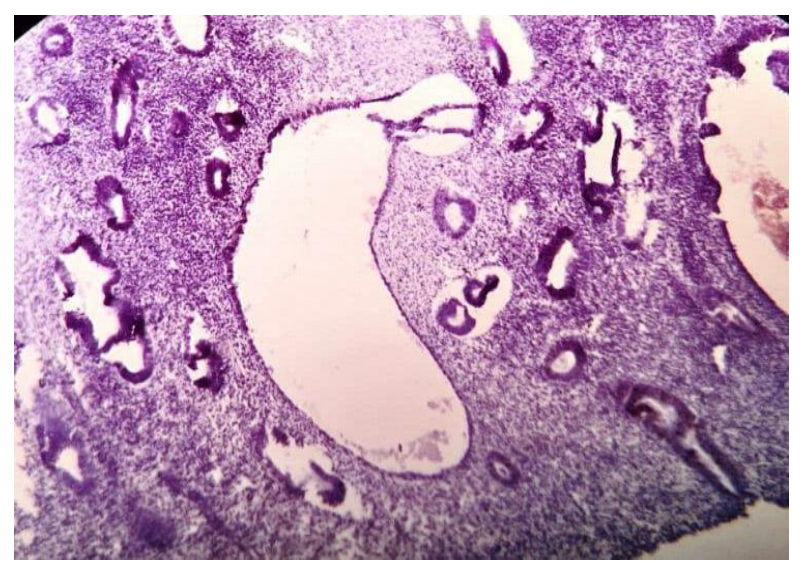

(5)

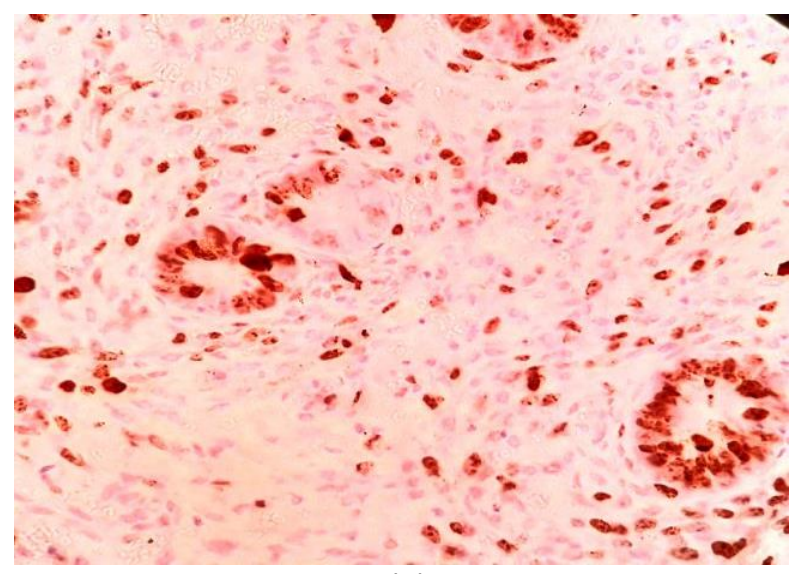

(6) 
Figure 5. A photomicrograph of histological section of endometrial layer of women with AUB show negative Ki67 in endometrial atrophy. (Ki67 expression $=0 \%$, intensity $=0$ ) (Ki67 IHC, 100x).

Figure 6. A photomicrograph of histological section of endometrial layer of women with AUB show positive Ki67 expression in chronic endometritis (Ki67 expression $=50 \%$, intensity $=1$ ) (Ki67 IHC, 400x).

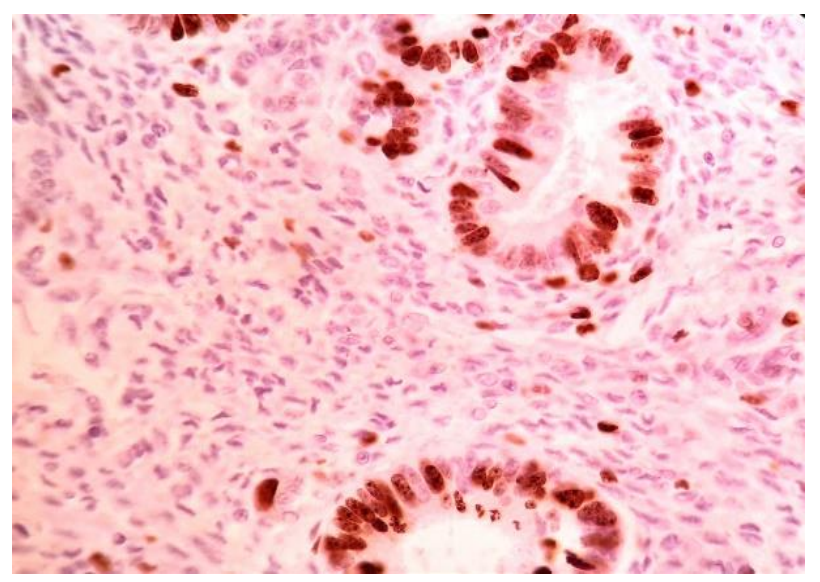

(7)

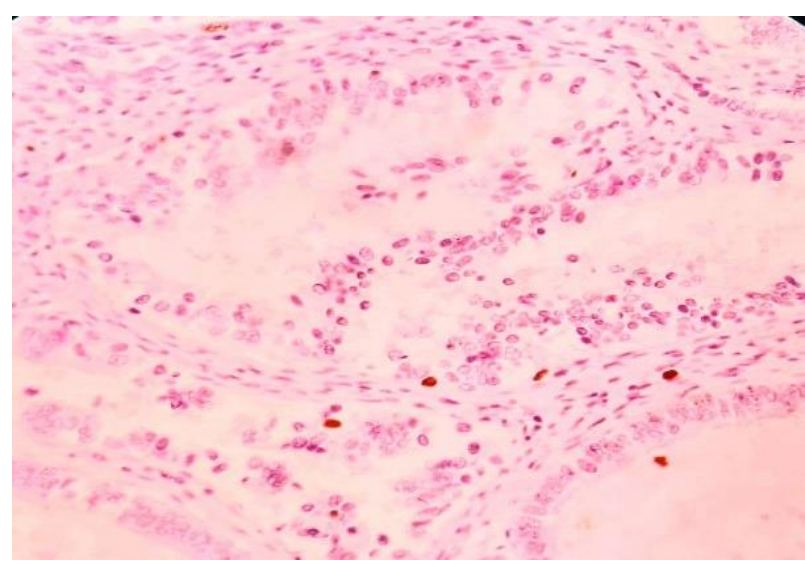

(8)

Figure 7. A photomicrograph of histological section of endometrial layer of women with AUB show positive Ki67 expression in endometrial polyp. (Ki67 expression $=70 \%$, intensity $=2) \quad(\mathrm{Ki} 67 \mathrm{IHC}$, 400x).

Figure 8. A photomicrograph of histological section of endometrial layer of women with AUB show negative Ki67 in well-differentiated endometrial adenocarcinoma ( $\mathrm{Ki} 67$ expression $=0$, intensity $=0$ ) (Ki67 IHC, 400x).

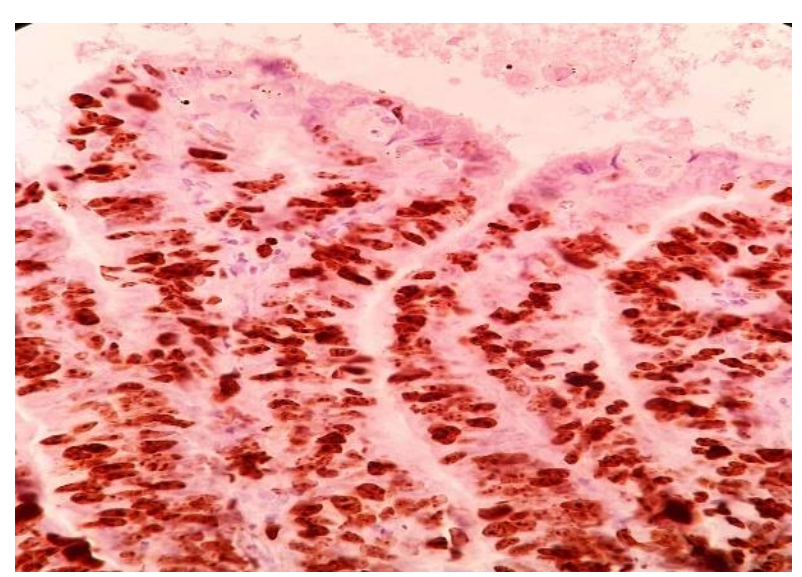

(9)

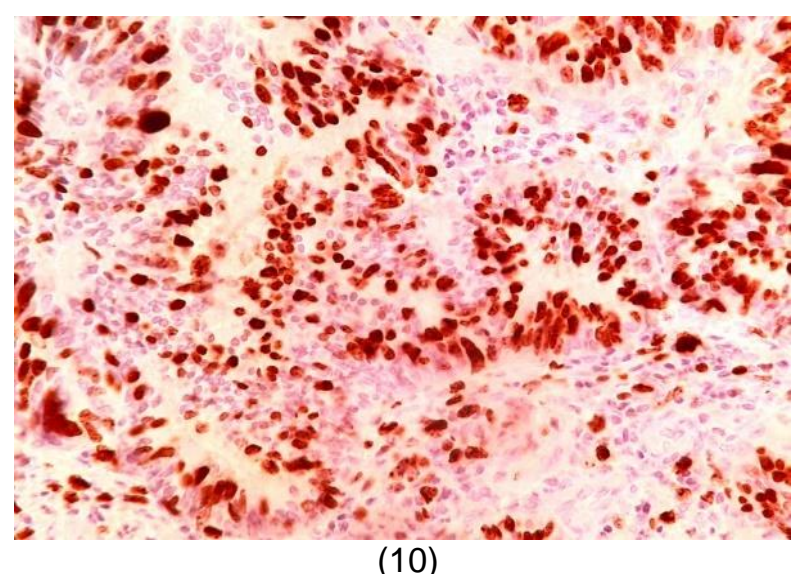

Figure 9. A photomicrograph of histological section of endometrial layer of women with AUB show positive Ki67 in moderately differentiated endometrial adenocarcinoma. (Ki67 expression $=90 \%$, intensity=3) (Ki67 IHC, 400x). Figure 10. A photomicrograph of a histological section of endometrial layer of women with AUB show positive Ki67 expression, dense nuclear staining in poorly differentiated endometrial adenocarcinoma. (Ki67 expression $=90 \%$, intensity=3) (Ki67 IHC, 400x).

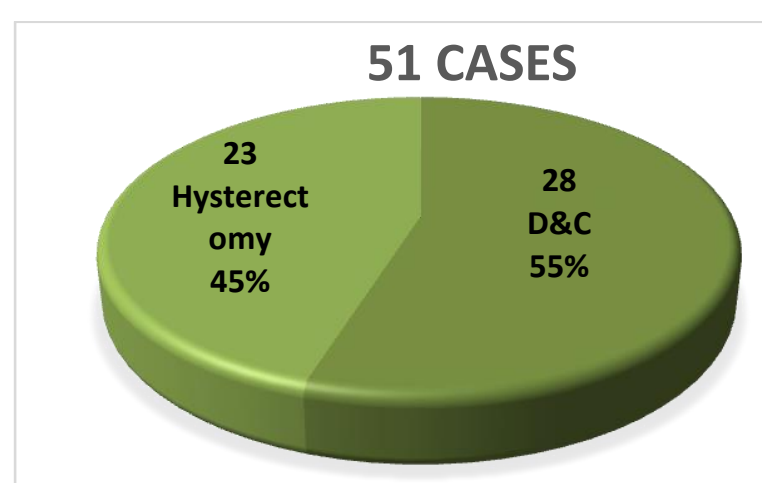

Figure 11. A histogram of the distribution of cases according to the method of the samples 'taking. 
Table 1. The Endometrial findings of the cases that enrolled in the immunohistochemical analysis of Ki67.

\begin{tabular}{|l|l|}
\hline Endometrial finding & No. (\%) \\
\hline Proliferative phase & $3(6 \%)$ \\
\hline Secretory phase & $5(10 \%)$ \\
\hline Mixed phase & $2(4 \%)$ \\
\hline Endometrial polyp & $3(6 \%)$ \\
\hline Endometrial atrophy & $1(2 \%)$ \\
\hline Endometritis & $2(4 \%)$ \\
\hline Hyperplasia without atypia & $9(17 \%)$ \\
\hline Hyperplasia with atypia & $6(12 \%)$ \\
\hline Endometrial adenocarcinoma & $20(39 \%)$ \\
\hline Total & $51(100 \%)$ \\
\hline
\end{tabular}

Table 2. The distribution of cases that presented with AUB according to the age.

\begin{tabular}{|l|l|l|l|l|}
\hline Age group & $\begin{array}{l}\text { Endometria } \\
\text { I carcinoma }\end{array}$ & $\begin{array}{l}\text { Endomet } \\
\text { hial } \\
\text { sia }\end{array}$ & $\begin{array}{l}\text { Benign } \\
\text { cases }\end{array}$ & $\begin{array}{l}\text { Total } \\
\text { No. (\%) }\end{array}$ \\
\hline $\begin{array}{l}\text { Reproductive } \\
18-40\end{array}$ & 0 & 3 & 7 & $10(20 \%)$ \\
\hline $\begin{array}{l}\text { Premenopausal } \\
41-50\end{array}$ & 5 & 5 & 8 & $18(35 \%)$ \\
\hline $\begin{array}{l}\text { Post- } \\
\text { menopausal } \\
>50\end{array}$ & 15 & 7 & 1 & $23(45 \%)$ \\
\hline Total & $20(39 \%)$ & $15(30 \%)$ & $16(31 \%)$ & $51(100 \%)$ \\
\hline
\end{tabular}

Table 3. The percentage of Ki67 expression among different lesions of endometrium in cases of AUB.

\begin{tabular}{|l|l|l|l|l|l|}
\hline \multirow{2}{*}{ Endometrial finding } & No. (\%) & \multicolumn{4}{|l|}{ Ki67 expression \% } \\
\cline { 3 - 6 } & & $1-25$ & $26-50$ & $51-75$ & $\begin{array}{l}76- \\
100\end{array}$ \\
\hline Proliferative phase & $3(6 \%)$ & 1 & 1 & 0 & 1 \\
\hline Secretory phase & $5(10 \%)$ & 5 & 0 & 0 & 0 \\
\hline Mixed phase & $2(4 \%)$ & 1 & 0 & 0 & 1 \\
\hline Endometrial polyp & $3(6 \%)$ & 2 & 0 & 1 & 0 \\
\hline $\begin{array}{l}\text { Endometrial } \\
\text { atrophy }\end{array}$ & $1(2 \%)$ & 1 & 0 & 0 & 0 \\
\hline Endometritis & $2(4 \%)$ & 1 & 1 & 0 & 0 \\
\hline $\begin{array}{l}\text { Hyperplasia } \\
\text { without atypia }\end{array}$ & $9(17 \%)$ & 8 & 1 & 0 & 0 \\
\hline $\begin{array}{l}\text { Hyperplasia with } \\
\text { atypia }\end{array}$ & $6(12 \%)$ & 6 & 0 & 0 & 0 \\
\hline $\begin{array}{l}\text { Endometrial } \\
\text { adenocarcinoma }\end{array}$ & $\begin{array}{l}20 \\
(39 \%)\end{array}$ & 12 & 2 & 1 & 5 \\
\hline Total & $\begin{array}{l}51 \\
(100 \%)\end{array}$ & $\begin{array}{l}37 \\
(72 \%)\end{array}$ & $\begin{array}{l}5 \\
(10 \%)\end{array}$ & $\begin{array}{l}2 \\
(4 \%)\end{array}$ & $\begin{array}{l}7 \\
(14 \%)\end{array}$ \\
\hline
\end{tabular}

Table 4. The intensity of Ki67 staining among different lesions of endometrium in cases of AUB.

\begin{tabular}{|c|c|c|c|c|c|}
\hline \multirow{2}{*}{$\begin{array}{l}\text { Endometrial } \\
\text { finding }\end{array}$} & \multirow{2}{*}{$\begin{array}{l}\text { No. } \\
(\%)\end{array}$} & \multicolumn{4}{|c|}{ Ki67 Intensity } \\
\hline & & $\mathrm{I}=0$ & $\mathrm{I}=1$ & $I=2$ & $I=3$ \\
\hline $\begin{array}{l}\text { Proliferative } \\
\text { phase }\end{array}$ & $3(6 \%)$ & 0 & 1 & 1 & 1 \\
\hline Secretory phase & $5(10 \%)$ & 2 & 2 & 1 & 0 \\
\hline Mixed phase & $2(4 \%)$ & 1 & 0 & 1 & 0 \\
\hline $\begin{array}{l}\text { Endometrial } \\
\text { polyp }\end{array}$ & $3(6 \%)$ & 0 & 0 & 3 & 0 \\
\hline $\begin{array}{l}\text { Endometrial } \\
\text { atrophy }\end{array}$ & $1(2 \%)$ & 1 & 0 & 0 & 0 \\
\hline Endometritis & $2(4 \%)$ & 0 & 2 & 0 & 0 \\
\hline $\begin{array}{l}\text { Hyperplasia } \\
\text { without atypia }\end{array}$ & $\begin{array}{l}9 \\
(17 \%)\end{array}$ & 1 & 4 & 4 & 0 \\
\hline $\begin{array}{l}\text { Hyperplasia with } \\
\text { atypia }\end{array}$ & $\begin{array}{l}6 \\
(12 \%)\end{array}$ & 0 & 5 & 1 & 0 \\
\hline $\begin{array}{l}\text { Endometrial } \\
\text { adenocarcinoma }\end{array}$ & $\begin{array}{l}20 \\
(39 \%)\end{array}$ & 1 & 10 & 5 & 4 \\
\hline Total & $\begin{array}{l}51 \\
(100 \%)\end{array}$ & $\begin{array}{l}6 \\
(10 \%)\end{array}$ & \begin{tabular}{|l}
24 \\
$(48 \%)$
\end{tabular} & $\begin{array}{l}16 \\
(32 \%)\end{array}$ & \begin{tabular}{|l|}
5 \\
$(10 \%)$
\end{tabular} \\
\hline
\end{tabular}

Table 5. The percentage of Ki67 expression among different age groups.

\begin{tabular}{|c|c|c|c|c|c|c|}
\hline \multirow{2}{*}{ Age group } & \multicolumn{4}{|c|}{ Ki67 expression \% } & \multirow{2}{*}{$\begin{array}{l}\text { Total } \\
\text { No. } \\
(\%)\end{array}$} & \multirow{2}{*}{$\begin{array}{l}\mathrm{p}- \\
\text { value }\end{array}$} \\
\hline & $1-25$ & $26-50$ & $51-75$ & $\begin{array}{l}76- \\
100\end{array}$ & & \\
\hline \begin{tabular}{|l|} 
Reproductive \\
$18-40$
\end{tabular} & $\begin{array}{l}6 \\
(12 \%)\end{array}$ & $1(2 \%)$ & $1(2 \%)$ & $2(4 \%)$ & $\begin{array}{l}10 \\
(20 \%)\end{array}$ & \multirow{4}{*}{0.740} \\
\hline $\begin{array}{l}\text { Premenopausa } \\
41-50\end{array}$ & $\begin{array}{l}14 \\
(27 \%)\end{array}$ & $2(4 \%)$ & $0(0 \%)$ & $2(4 \%)$ & $\begin{array}{l}18 \\
(35 \%)\end{array}$ & \\
\hline $\begin{array}{l}\text { Post- } \\
\text { menopausal } \\
>50\end{array}$ & $\begin{array}{l}17 \\
(33 \%)\end{array}$ & $2(4 \%)$ & $1(2 \%)$ & $3(6 \%)$ & $\begin{array}{l}23 \\
(45 \%)\end{array}$ & \\
\hline Total & $\begin{array}{l}37 \\
(72 \%)\end{array}$ & $\begin{array}{l}5 \\
(10 \%)\end{array}$ & $2(4 \%)$ & $\begin{array}{l}7 \\
(14 \%)\end{array}$ & \begin{tabular}{|l|}
51 \\
$(100 \%)$
\end{tabular} & \\
\hline
\end{tabular}

Table 6. The intensity of Ki67 expression among different age groups.

\begin{tabular}{|c|c|c|c|c|c|}
\hline \multirow{2}{*}{ Age group } & \multicolumn{4}{|c|}{ Ki67 intensity } & \multirow{2}{*}{$\begin{array}{l}\text { Total } \\
\text { No. } \\
(\%)\end{array}$} \\
\hline & $I=0$ & $I=1$ & $I=2$ & $I=3$ & \\
\hline \begin{tabular}{|l} 
Reproductive \\
$18-40$
\end{tabular} & $4(8 \%)$ & $2(4 \%)$ & \begin{tabular}{|l|}
3 \\
$(6 \%)$
\end{tabular} & $\begin{array}{l}1 \\
(2 \%)\end{array}$ & $\begin{array}{l}10 \\
(20 \%)\end{array}$ \\
\hline $\begin{array}{l}\text { Premenopausal } \\
41-50\end{array}$ & $0(0 \%)$ & 7 (14\%) & $\begin{array}{l}9 \\
(17 \%)\end{array}$ & $\begin{array}{l}2 \\
(4 \%)\end{array}$ & $\begin{array}{l}18 \\
(35 \%)\end{array}$ \\
\hline $\begin{array}{l}\text { Post- } \\
\text { menopausal } \\
>50\end{array}$ & $\begin{array}{l}2 \\
(4 \%)\end{array}$ & $\begin{array}{l}14 \\
(27 \%)\end{array}$ & $\begin{array}{l}5 \\
(10 \%)\end{array}$ & $\begin{array}{l}2 \\
(4 \%)\end{array}$ & $\begin{array}{l}23 \\
(45 \%)\end{array}$ \\
\hline Total & $\begin{array}{l}6 \\
(12 \%)\end{array}$ & $23(45 \%)$ & $\begin{array}{l}17 \\
(33 \%)\end{array}$ & \begin{tabular}{|l}
5 \\
$(10 \%)$ \\
\end{tabular} & $\begin{array}{l}51 \\
(100 \%)\end{array}$ \\
\hline
\end{tabular}


Table 7. The mean percentage of Ki67 expression and mean of Intensity among different lesions of endometrium in cases of AUB.

\begin{tabular}{|c|c|c|c|c|}
\hline $\begin{array}{l}\text { Endometrial } \\
\text { findings }\end{array}$ & $\begin{array}{l}\text { No. } \\
(\%)\end{array}$ & $\begin{array}{l}\text { Mean } \\
\text { of Ki67 } \\
\text { Intensi } \\
y\end{array}$ & $\begin{array}{l}\text { Mean of } \\
\text { Ki67 } \\
\text { texpression } \\
\%\end{array}$ & $p$-value \\
\hline $\begin{array}{l}\text { Proliferative } \\
\text { phase }\end{array}$ & $\begin{array}{l}3 \\
(6 \%)\end{array}$ & 2 & 40.6 & \multirow{10}{*}{$\begin{array}{l}\text { For mean } \\
\text { of Ki67 } \\
\text { expressio } \\
\mathrm{n} \% \\
=0.134 \text {, } \\
\text { while for } \\
\text { mean } \\
\text { intensity is } \\
<0.05\end{array}$} \\
\hline $\begin{array}{l}\text { Secretory } \\
\text { phase }\end{array}$ & $\begin{array}{l}5 \\
(10 \%)\end{array}$ & 0.8 & 2.8 & \\
\hline Mixed phase & $\begin{array}{l}2 \\
(4 \%)\end{array}$ & 1 & 40 & \\
\hline $\begin{array}{l}\text { Endometrial } \\
\text { polyp }\end{array}$ & \begin{tabular}{|l|}
3 \\
$(6 \%)$
\end{tabular} & 2 & 36.7 & \\
\hline $\begin{array}{l}\text { Endometrial } \\
\text { atrophy }\end{array}$ & $1(2 \%)$ & 0 & 0 & \\
\hline Endometritis & $\begin{array}{l}2 \\
(4 \%)\end{array}$ & 1 & 29 & \\
\hline $\begin{array}{l}\text { Hyperplasia } \\
\text { without atypia }\end{array}$ & $\begin{array}{l}9 \\
(17 \%)\end{array}$ & 1.3 & 13.1 & \\
\hline $\begin{array}{l}\text { Hyperplasia } \\
\text { with atypia }\end{array}$ & $\begin{array}{l}6 \\
(12 \%)\end{array}$ & 1.2 & 14.3 & \\
\hline $\begin{array}{l}\text { Endometrial } \\
\text { adenocarcino } \\
\text { ma }\end{array}$ & $\begin{array}{l}20 \\
(39 \%)\end{array}$ & $1.65^{*}$ & 34 & \\
\hline Total No.=51 & $\begin{array}{l}51 \\
(100 \\
\%) \\
\end{array}$ & 1.22 & 23.38 & \\
\hline
\end{tabular}

Table 8. Ki67 Expression in different cases of AUB.

\begin{tabular}{|c|c|c|c|c|c|}
\hline \multirow{2}{*}{$\begin{array}{l}\text { Endometrial } \\
\text { cases }\end{array}$} & \multicolumn{4}{|c|}{ Ki67 expression \% } & \multirow{2}{*}{$\begin{array}{l}p- \\
\text { value }\end{array}$} \\
\hline & $1-25$ & $26-50$ & $\begin{array}{l}51- \\
75\end{array}$ & $\begin{array}{l}76- \\
100\end{array}$ & \\
\hline $\begin{array}{l}\text { Benign cases } \\
\text { No. }=16\end{array}$ & $\begin{array}{l}11 \\
(20 \%)\end{array}$ & $\begin{array}{l}2 \\
(4 \%)\end{array}$ & 1 & $2(4 \%)$ & \multirow{4}{*}{ k0.05 } \\
\hline $\begin{array}{l}\text { Endometrial } \\
\text { hyperplasia } \\
\text { No. }=15\end{array}$ & $\begin{array}{l}14 \\
(28 \%)\end{array}$ & 1 & $\begin{array}{l}0 \\
(0 \%)\end{array}$ & $0(0 \%)$ & \\
\hline $\begin{array}{l}\text { Endometrial } \\
\text { adenocarcinoma } \\
\text { No. }=20\end{array}$ & $\begin{array}{l}12 \\
(24 \%)\end{array}$ & $\begin{array}{l}2 \\
(4 \%)^{*}\end{array}$ & $\begin{array}{l}1 \\
(2 \%)^{*}\end{array}$ & * $\begin{array}{l}5 \\
(10 \%)^{*}\end{array}$ & \\
\hline Total No. $=51$ & $\begin{array}{l}37 \\
(72 \%)\end{array}$ & $\begin{array}{l}5 \\
(10 \%)\end{array}$ & $\begin{array}{l}2 \\
(4 \%)\end{array}$ & $\begin{array}{l}7 \\
(14 \%)\end{array}$ & \\
\hline
\end{tabular}

Table 9. Percentage of Ki67 expression and Ki67 intensity in cases of endometrial hyperplasia.

\begin{tabular}{|c|c|c|c|c|}
\hline Parameters & & $\begin{array}{l}\text { Endome } \\
\text { hyperpla } \\
\text { Without } \\
\text { atypia }\end{array}$ & $\begin{array}{l}\text { trial } \\
\text { asia } \\
\text { With } \\
\text { atypia }\end{array}$ & $\begin{array}{l}\text { No. } \\
(\%)\end{array}$ \\
\hline \multirow{3}{*}{ Age groups } & $\begin{array}{l}\text { Reproductive } \\
(18-40)\end{array}$ & $2(13 \%)$ & $1(7 \%)$ & $\begin{array}{l}3 \\
(20 \%)\end{array}$ \\
\hline & $\begin{array}{l}\text { Premenopau } \\
\text { sal }(41-50)\end{array}$ & $4(27 \%)$ & $1(7 \%)$ & \begin{tabular}{|l}
5 \\
$(34 \%)$
\end{tabular} \\
\hline & $\begin{array}{l}\text { Postmenopa } \\
\text { usal }(>50)\end{array}$ & $3(20 \%)$ & $\begin{array}{l}4 \\
(26 \%)\end{array}$ & $\begin{array}{l}7 \\
(46 \%)\end{array}$ \\
\hline \multirow{4}{*}{$\begin{array}{l}\text { Ki67 } \\
\text { expression } \\
\%\end{array}$} & $0-25$ & $7(46 \%)$ & $\begin{array}{l}6 \\
(40 \%)\end{array}$ & \begin{tabular}{|l|}
13 \\
$(86 \%)$
\end{tabular} \\
\hline & $26-50$ & $1(7 \%)$ & $1(7 \%)$ & $\begin{array}{l}2 \\
(14 \%)\end{array}$ \\
\hline & $51-75$ & $0(0 \%)$ & $0(0 \%)$ & $0(0 \%)$ \\
\hline & 76-100 & $0(0 \%)$ & $0(0 \%)$ & $0(0 \%)$ \\
\hline \multirow{4}{*}{ Ki67 intensity } & $I=0$ & $1(7 \%)$ & $0(0 \%)$ & $1(7 \%)$ \\
\hline & $I=1$ & $4(26 \%)$ & $\begin{array}{l}5 \\
(34 \%) \\
\end{array}$ & $\begin{array}{l}9 \\
(60 \%) \\
\end{array}$ \\
\hline & $I=2$ & $4(26 \%)$ & $1(7 \%)$ & \begin{tabular}{|l}
5 \\
$(33 \%)$
\end{tabular} \\
\hline & $I=3$ & $0(0 \%)$ & $0(0 \%)$ & $0(0 \%)$ \\
\hline
\end{tabular}

Table 10. Percentage of Ki67 expression and Ki67 intensity in different age groups in cases of endometrial adenocarcinoma.

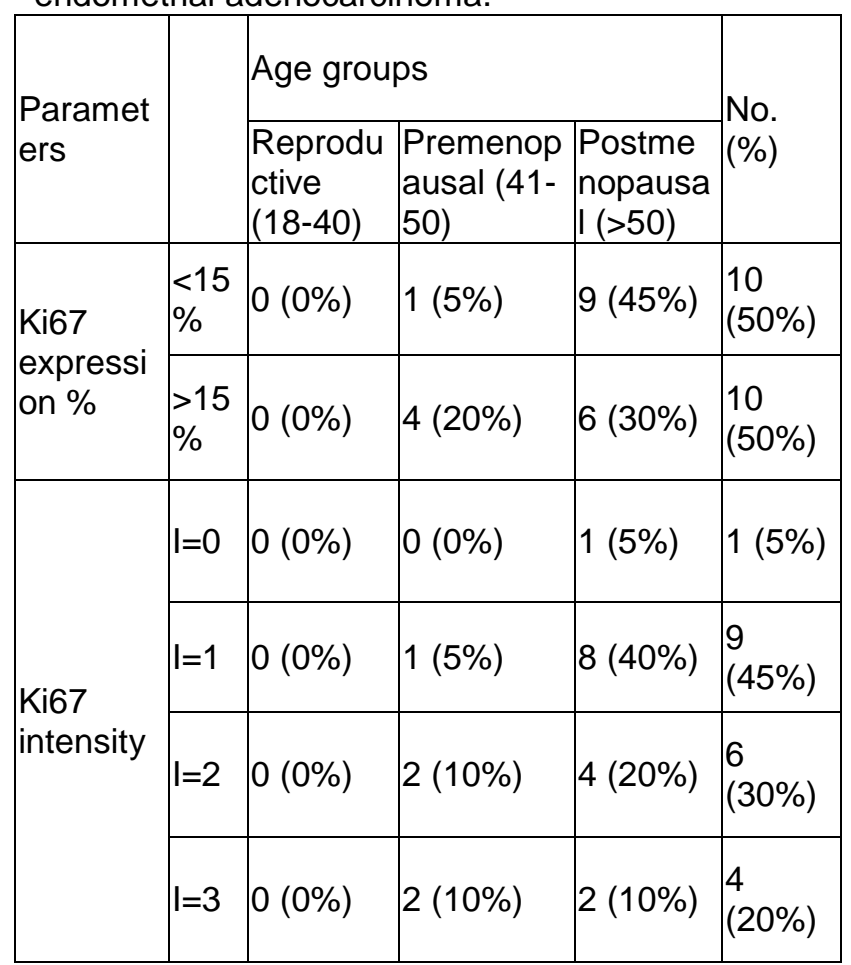


Table 11. Relation of differentiation of endometrial adenocarcinoma with Ki67 parameters.

\begin{tabular}{|c|c|c|c|c|c|}
\hline \multirow[b]{2}{*}{ Parameters } & & \multicolumn{3}{|c|}{ Differentiation } & \multirow{2}{*}{$\begin{array}{l}\text { No. } \\
(\%)\end{array}$} \\
\hline & & $\begin{array}{l}\text { Well } \\
\text { diff. AC }\end{array}$ & $\begin{array}{l}\text { Mod. } \\
\text { diff. AC }\end{array}$ & $\begin{array}{l}\text { Poorly } \\
\text { diff. AC }\end{array}$ & \\
\hline \multirow{2}{*}{$\begin{array}{l}\text { Ki67 } \\
\text { expression \% }\end{array}$} & $<15 \%$ & $\begin{array}{l}3 \\
(15 \%)\end{array}$ & $\begin{array}{l}5 \\
(25 \%)\end{array}$ & $\begin{array}{l}2 \\
(10 \%)\end{array}$ & $\begin{array}{l}10 \\
(50 \%) \\
\end{array}$ \\
\hline & $>15 \%$ & $\begin{array}{l}2 \\
(10 \%)\end{array}$ & $\begin{array}{l}5 \\
(25 \%)\end{array}$ & $\begin{array}{l}3 \\
(15 \%)\end{array}$ & $\begin{array}{l}10 \\
(50 \%)\end{array}$ \\
\hline \multirow{4}{*}{ Ki67 intensity } & $I=0$ & $1(5 \%)$ & $0(0 \%)$ & $0(0 \%)$ & $1(5 \%)$ \\
\hline & $\mathrm{I}=1$ & $\begin{array}{l}2 \\
(10 \%)\end{array}$ & $\begin{array}{l}5 \\
(25 \%)\end{array}$ & $\begin{array}{l}2 \\
(10 \%)\end{array}$ & $\begin{array}{l}9 \\
(45 \%)\end{array}$ \\
\hline & $I=2$ & 1 (5\%) & $3(15 \%)$ & $2(10 \%)$ & $6(30 \%)$ \\
\hline & $I=3$ & 1 (5\%) & $2(10 \%)$ & 1 (5\%) & $4(20 \%)$ \\
\hline
\end{tabular}

\section{DISCUSSION}

In fact, In Nineveh Province, there was one immunohistochemical study that was conducted on paraffin blocks of cases of endometrial carcinoma in this locality, and authors found that estrogen receptor- ER a - is found in $60 \%$ of cases of endometrial carcinoma and suggested that its expression has an inverse relation with the grading of carcinoma beside the degree of myometrial invasion $^{32}$.

The endometrial biopsy is an ideal tool for diagnosis and evaluation of endometrial condition (benign and malignant). Ki67 may have a play a role to diagnose malignancies as factor for prognosis that assist in the treatment ${ }^{36}$, as it has high percentage in cases of sections of cancer, while its percentage was low in cases of endometrial hyperplasia especially without atypia 37

The current immunohistochemical study revealed that $\mathrm{Ki} 67$ expression was positive in all cases of endometrial cancer. These findings are in accordance with those of others ${ }^{33-35,38}$.

On the other hand, moderate levels of Ki67 expression shown in cases of hyperplasia with atypia. The current findings of this study are similar to those of other works ${ }^{38-40}$, further researches are needed to clarify the role of Ki67 expression in cases of AUB in our locality.

There a potential correlation between breast malignant tumor's aggressiveness and the neoplastic cells' proliferation, and this identified via immunohistochemical detection of proliferative index (Ki67). American Society of Clinical Oncology (ASCO) has not recommend the utility of $\mathrm{Ki}-67$ as a routine for prediction of the endometrial cancer's outcomes ${ }^{23}$.

A precise assessment of the tumor proliferation is of great significance for excluding of cases with slow proliferating of tumor cells and for avoiding the overtreatment ${ }^{11}$.

Among the proteins that in general is associated with proliferation and growth of tumor cells is a nuclear protein-Ki67, so it is considered as an excellent marker as the cancer cells are characterized by their higher proliferation rate ${ }^{29,38}$.

Physically, the quantification of Ki67 is a direct measurement of the proliferative activity of a cell. Immunohistochemical stains is an effective method to assess the proportion of tumor cells. Nowadays, various techniques are present to count $\mathrm{Ki} 67$ in different forms of cancer ${ }^{23,29}$.

The most widely measurement of the proliferation status of tumors via Ki67 as a good clinical marker for decisions for treatment ${ }^{11}$.

Comprehensively, the recommendations (preanalytical and analytical assessment) beside interpret and score of immunohistochemical expression of Ki67 which were approved by the International Working Group that concerning with Ki67 in Cancer of breast in 2011 were used ${ }^{11,23}$.

This work showed variable expressions of Ki67 among spectrum of endometrial lesions. These findings are similar to those of Adomaitiene et al, $2019^{11}$, and those of Shalini et al, $2019^{29}$.

Analysis of immunohistochemical expression of Ki67 in sections of women presented with AUB revealed that there is a relation with the age of patients. Similar observation was found in works of Jiang et al, 2020; Gharib et al, 2020 ${ }^{30,41}$.

On the contrary, this work concluded that the highest mean of percentage of Ki67 expression was in sections of proliferative endometrium. These findings are similar to those of other studies which revealed that similar pattern of high proliferative activity in glandular epithelium in cases of proliferative endometrium ${ }^{29,38}$.

The expression of Ki67 normally enhanced throughout the proliferative phase of the menstrual cycle, 11 .

On the other hand, this study revealed the low proliferative activity in glandular epithelium in cases with secretory endometrium (mean percentage $=2.8 \%$ ). The findings of the current study are in accordance with those of Shalini et al, $2019^{29}$, who reported that the mean percentage of Ki67 expression was $29 \%$ and $3.6 \%$ in sections of proliferative endometrium and secretory endometrium respectively. In fact, the difference in values of mean percentage of $\mathrm{Ki} 67$ expression between studies may be due to the differences in the methodology.

The most frequent immunohistochemical staining way to elucidate Ki67 expression is via MIB-1 antibody. Various antibodies such as Ki-S5, MIB-1, MM-1, and SP-6 utilized in different researches. This could be an explanation for this considerable 
difference. Different groups of population may be the cause. There is a difference in the methodology to detect Ki67 with various cutoffs to distinct a low Ki67 expression from a high. Moreover, there is a variation in the scoring of Ki67 as some of the pathologists utilize the percentage of nuclear staining, while others observe several hundred nuclei in various regions of tumors to obtain the overall average index ${ }^{22,23}$.

This work showed a strong positive correlation in Ki67 staining between the glandular compartments in most of the types of endometrium lesions, also showing statistically marked differences between the same groups. This may mean that the estrogen is a mediator of proliferative process and as indicated by the comparable values of Ki67 marker in different tissue ${ }^{11}$.

On the other hand, a high expression of Ki67 shown in sections of polyp; however, the highest mean of that expression was in those of low age. This finding indicated that the processes of proliferation is essential in the polyp's pathogenesis and goes with the hypothesis that estrogen encourages endometrial lining's proliferation and growth, whereas progesterone acts as antagonist for estrogen-driven growth and assists differentiation ${ }^{11,23}$

Glands with little proliferating mode were notinfrequent after menopause as the uterine mucosa responded to sustain stimulation of estrogen even it is low. The postmenopausal women possess an increased capability for androstendione's conversion, mostly that from adrenal gland, into estrone in the fatty tissues of the body due to the effect of aromatase ${ }^{11,42}$.

A motivating observation in this study indicated that the cases of polyp exhibited features of low proliferative activity (low positive immunoreactivity) in comparison with those of endometrial carcinoma. Authors considered such findings as a favorable prognosis for any case of polyp ${ }^{11}$.

This work showed that $11 / 16(68.8 \%)$ cases of benign causes of AUB exhibited Ki67 expression of less than $25 \%$. These findings are according to those of Shalini et al, 2019, and of Zimik et al, $2020^{28,29}$.

On the other hand, 14/15 (93\%) cases of endometrial hyperplasia presented with Ki67 expression of less than $25 \%$. These observations were similar to those of other workers, who observed increased Ki67 expression in cases of endometrial hyperplasia with or without atypia to cases of endometrial carcinoma when compared with those in benign conditions ${ }^{28,29,38}$.

The current study revealed that Ki67 found positive in most cases of endometrial hyperplasia with a $13 \%$ and $14 \%$ as mean percentage of positivity in hyperplasia without atypia and atypical hyperplasia respectively. The positivity varied from $0 \%$ to $25 \%$ in non-atypical hyperplasia group and $5 \%$ to $25 \%$ in atypical hyperplasia group. Our observations were similar to those of Shalini et al, $2019^{29}$.As hyperplasia progresses toward atypia; there is a decrease in apoptosis with increased proliferation. Therefore, Ki67 expression with Bcl2 may have some role as a marker of endometrial hyperplasia progression to carcinoma ${ }^{29}$.

In fact, Doherty reported that a $30 \%$ of cases with atypical form of hyperplasia had synchronously endometrial cancer, however, the data of reports (especially -population -based) not satisfactory, but atypia progression to carcinoma was high ${ }^{8}$.

As shown in our study, Stoenescu, reported that cases of hyperplasia and carcinoma showed more intensity of Ki67 staining in comparison with those of benign conditions ${ }^{43}$.

In cases of hyperplasia, Ki67 index was not high and its expression is raised as there is a disease progression from atypical hyperplasia to carcinoma as shown by study of Masood et al, $2017^{44,45}$.

Specialized histopathological lesions formulated as endometrial hyperplasia sometimes forego endometrial (endometrioid) carcinoma and presently it believed there is a series of alterations that progressed to endometrioid carcinoma ${ }^{38}$.

Hyperplasia in usual is correlated with exogenous estrogen stimulation, so estrogen is regarded as an endometrial carcinogen ${ }^{43}$.

Regarding the cases of carcinoma, this study revealed that $8 / 20(40 \%)$ of sections exhibited expression of the Ki67 of more than $25 \%$. Similar observation was found by others ${ }^{23,29,30,41}$.

The approximate mean percentage of expression of the Ki67 positive cells in carcinoma of the colon, skin, and bladder are 40\%-70\%, while that of endometrial carcinoma ranged from $2 \%$ to $30 \%{ }^{11}$.

The mean percentage of expression of $\mathrm{Ki} 67$ in cases of cases of carcinoma in this work was 34\%. These observations were similar to those of Zimik et al who reported high expression of Ki67 noticed in cases with endometrial cancers ${ }^{28}$.

A study of Al-Nuaimi et al, $2020^{23}$, reported that the immune-expression of Ki67 was shown in $(45 \%)$ of the females of the carcinoma of breast in Nineveh province.

Carcinogenesis is a multiple -steps process that enrolls the induction of mutational activation in tumor suppressor genes, increased cellular proliferation and angiogenesis for tumor growth ${ }^{11}$.

To detect biomarkers, which have potential importance in several cancer types, immunohistochemistry may be useful. Ki67 among markers that can utilized for purposes (diagnostic and prognostic) in endometrial carcinoma ${ }^{22}$. 
A number of studies describe $\mathrm{Ki} 67$ as a prognostic biomarker, showing correlation between Ki67 score and well-known pathological prognostic parameters of endometrial carcinoma as grade, stage, myometrial invasion's depth, and cancer outcomes $^{30,41}$.

Jiang et al, $2020^{41}$ reported a correlation between expression of the Ki67 score and histotype, estrogen receptors, progesterone receptors. He showed that cut off value of $38 \%$ to predict the cancer recurrence.

On the other hand, Gharib et al, $2020{ }^{30}$ concluded that there is a marked association between expression of the Ki67 and poor tumor characteristics.

Regarding this work, there was increase in expression of $\mathrm{Ki} 67$ in cases of endometrial carcinoma in comparison with those with proliferative endometrium, hyperplasia, endometritis and polyp ${ }^{38}$.

Mean Ki67 values were higher in cases with proliferative endometrium compared to carcinomas and hyperplasia $(P<0.01)$ and there is a marked variation was noticed between the mean Ki67 values of cases with proliferative endometrium and hyperplasia.

Authors reported Ki67 are positive in all types of endometria with active mitosis: proliferative, hyperplastic, and all kinds of carcinoma and suggested that Cyclin D1 expression of more than $30 \%$ accompanied with Ki67 expression of more than $30 \%$ may be considered as an indication of atypical hyperplasia, whereas a Ki67 expression of more than $57 \%$ in the same is marker of endometrial carcinoma ${ }^{38}$.

In the present work, the $p$ value for expression of Ki67 was statistically significant for hyperplasia versus endometrial carcinomas as seen in those of another work ${ }^{5}$.

In the perimenopausal years an ovulatory cycles are so common that cause alterations in the endometrium which in turn and leads to irregular bleeding. Perimenopause as World Health Organization (WHO) defined it as the two to eight years before menopause and the one-year beyond the final menstrual cycle.

In the present study, high Ki67 labeling index seen in all cases of endometrial carcinoma whereas low Ki67 labeling index observed in all cases of endometrial hyperplasia. Moderate Ki67 was seen in 2 cases of hyperplasia. These findings are similar to those of Li et al ${ }^{14}$ and of Zidan et al, $2015^{40}$ who observed increased Ki67 positivity in endometrial carcinoma compared to endometrial hyperplasia, however, Shevra et al, $2015^{34}$ also found high Ki67 labeling index in one hundred percent of endometrial carcinoma but it is high also in $77.65 \%$ of endometrial hyperplasias.
The limitation of the current study is the sample size is small. There is a need for a larger sample size to give a better perception for the various endometrial findings in cases, which are presenting with AUB in clinical practice ${ }^{28}$.

The relation of Ki67 expression with the age of the patients was not statistically significant $(P<0.05)$, this result is similar to that of others, however the $\mathrm{Li}$ et al.2019 ${ }^{14}$ found a significant relation of $\mathrm{Ki} 67$ with the age, that patients with high -Ki67-expression were younger than those with lower Ki67 expression.

A precise marked correlation between the $\mathrm{Ki} 67$ expression and tumor grade been registered in several reports. A similar result was observe in the current study. One of the three components of the modified Bloom-Richardson grading system of breast cancer was the mitotic index. It well known that there is an association between histologic grade and poor prognosis. In current study Ki67, expression found to increase with increasing the tumor's grade. This is in accordance with the welldocumented view, that proliferating cells do not differentiate in usual while cells when differentiating usually, their dividing stopped. In addition, Ki67 scores related to endometrial carcinoma's grade ${ }^{38}$.

In the study of Al-Nuaimi concluded that the cases breast cancer that has high Ki67 expression, there is a poor prognosis, however, the response is better to Neoadjuvant Chemotherapy, as there is an increase in sensitivity to cytotoxic drugs by the dividing cells.

In the breast cancer, Ki67 expression regarded as a predictive marker in addition to added estrogen and progesterone receptors for prognosis prediction. In fact, a large prospective work among cases with endometrial and breast cancer with different Ki67 expression and various added estrogen and progesterone receptors cancer phenotypes is required to identify the role of Ki67 in prognosis and prediction ${ }^{23}$.

Among various endometrial tumor sampling protocols, the most consistently reported is the hot spot scoring and it is the best fruitful tool to score Ki67. It has an excellent intra observer agreement and inter -observer agreement in comparison with whole slide and invasive edge scoring system. It has a marked importance for window studies that use Ki67 primarily as outcome measure. The endometrial biopsy taken before the intervention commonly found in comparison with the hysterectomy's specimen that is finally beyond the treatment to identify the response ${ }^{22}$.

Mean percentage of Ki67 expression in section of endometrial carcinomas in the current work was similar to that of other studies, Liu et al, $2014^{46}$, 
who utilized Ki67 median to disconnect tumors into high and low Ki67 expression ${ }^{22}$.

As one of primarily used outcome measure, there is an increase in the role of $\mathrm{Ki67}$ as window (pre-surgical) researches in endometrial cancer. Not as the case of breast cancer, however, the guidelines optimizing its measurements is lacking and its clinically relevant value as a responsebiomarker is not determined yet. Therefore, it is crucial that Ki67 scoring protocols are standardized and its correlation with patients survival need to be thoroughly assessed, to be capable for clinical interpretation of the data of these studies ${ }^{23}$.

Depending on the international working group, guidelines of Ki67 in breast cancer, whole slide, hot spot and invasive edge scoring strategies should be advocated ${ }^{23}$.

Ideally, this should include examining the similar novelty of therapy prior and beyond surgical operation and assess changes in pre-surgically Ki67 score beside longer-term cancer-specialized and recurrence free survival as outcomes variables. Depending on baseline, Ki67 score, the stratification of the response to treatment is performed $^{22}$.

Further work needed to correlate the Ki67 score with pathologically specific prognostic parameters, including grade, stage, and myometrial invasion's depth. Authors reported high Ki67 was relate with poor cancer outcomes; however, it is not independent of other factors of prognosis ${ }^{23}$.

On the other hand, studies and suggested that there is a deregulation of cellular proteins (mutations in PTEN tumor suppressor, and p53 genes), and therefore they may contribute in endometrial carcinogenesis ${ }^{45-47}$, such these works are suggested in our locality in future.

Moreover, further work is recommended to study the expression of estrogen receptor, progesterone receptor, p53 and Ki67 in cases of endometrial carcinomas ${ }^{46,47}$. Follow up studies are needed to elucidate the Ki67 expression after chemotherapy as authors observed that Ki67 was markedly decrease after chemotherapy, also they observed that the cases with breast cancer and show negative estrogen receptor but high Ki67 expression have better response ${ }^{48,49}$.

In conclusions: Analysis of immunohistochemical expression of $\mathrm{Ki} 67$ in sections of women presented with AUB revealed that there is a relation with the age of patients. A significant association between expression of the Ki67 and poor tumor characteristics concluded. Significant differences was shown between the expression of the $\mathrm{Ki} 67$ in sections of proliferative phase and those of endometrial hyperplasia ,while significant differences was found between the expression of the Ki67 in sections of endometrial hyperplasia and those of endometrial carcinoma. Using of Ki67 as diagnostic and prognostic tool in endometrial carcinoma may be conclude.

\section{ACKNOWLEDGMENT}

Thanks to all females who participate with their data in this work. Special thanks to the staff of AlBatool Teaching Hospital, Al- Khansaa Teaching Hospital, Al-Salam Teaching Hospital, Al-Rabeeh Private Hospital, and Al-Zahrawy Private Hospital at Mosul Province, Northern Iraq for their kind help. Authors are grateful to the staff of Unit of Immunohistochemistry in Vin Hospital -DuhokNorth of Iraq for helpful comments.

\section{REFERENCES}

1.Munro M.G., Critchley H., Fraser I.S. Research and clinical management for women with abnormal uterine bleeding in the reproductive years: More than PALM-COEIN. 2017; 124:1859.

2.Munro M.G. Southern California Permanente Medical Group's Abnormal Uterine Bleeding Working Group. Investigation of women with postmenopausal uterine bleeding: Clinical practice recommendations. Perm. J. 2014; 18:55-70.

3.Stachowicz N., Smole'n A., Ciebiera M., Lozinski T., Poziemski P., Borowski D., et al. Risk Assessment of Endometrial Hyperplasia or Endometrial Cancer with Simplified UltrasoundBased Scoring Systems. MDPI. 2021; 11(442):114.

4.Sobczuk K., Sobczuk A. New classification system of endometrial hyperplasia WHO 2014 and its clinical implications. Menopausal Rev. 2017; 3(3):107-11.

5.Swami R.M., Lakhe R., Doshi P., Karandikar M.N., Nimbargi R., Mani N.S. Immunohistochemical study of ER, PR, p53 and Ki67 expression in patients with endometrial adenocarcinoma and atypical endometrial hyperplasia. IP Archives of Cytology and Histopathology Research. 2020; 5(4):274-9.

6.Dore M., Filoche S., Danielson K., Henry C. Efficacy of the LNG-IUS for treatment of endometrial hyperplasia and early stage endometrial cancer: Can biomarkers predict response? Gynecologic Oncology Reports. 2021; 36: 100732.

7.Hassan W.A., Ibrahim R. Expression of CD117, CD34, and VEGF proteins in progression from endometrial hyperplasia to endometrioid carcinoma. Int J Clin Exp Pathol. 2020; 13(8):2115-22. 
8.Doherty M.T., Sanni O.B., Coleman H.G., Cardwell C.R., McCluggage G., Quinn D., et al. Concurrent and future risk of endometrial cancer in women with endometrial hyperplasia: $A$ systematic review and meta-analysis. PLOS ONE. 2020; https://doi.org/10.1371/journal.pone.0232231.

9. Laas E., Ballester M., Cortez A., Gonin J., Canlorbe G., Darai E., et al. Supervised clustering of immunohistochemical markers to distinguish atypical and non-atypical endometrial hyperplasia. Gynecol Endocrinol. 2015; 31:2825.

10. Ellenson L.H., Ronnett B.M., Kurman R.J. Precursor lesions of endometrial carcinoma. In: RJ Kurman , LH Ellenson, BM Ronnett, editors. Blaustein's Pathology of the Female Genital Tract. Springer, Boston, MA; (2011).

11. Adomaitiene L., Nadišauskiene R., NickkhoAmiry M., Cizauskas A., Palubinskiene J., Hlland C., et al. Proliferation in postmenopausal endometrial polyp- A potential for malignant transformation. Medicina. 2019; 55(543):1-12.

12. Ferlay J., Soerjomataram I., Dikshit R., Eser S., Mathers C., Rebelo M., et al. Cancer incidence and mortality worldwide: sources, methods and major patterns in GLOBOCAN 2012. Int J cancer 2015; 136:359-386.

13. Yuk J.S. The incidence rates of endometrial hyperplasia and endometrial cancer: a four-year population-based study. Peer J. 2016; 4:e2374.

14. Li W., Wang S., Qiu C., Liu Z., Zhou Q., Kong D., et al. Comprehensive bioinformatics analysis of acquired progesterone resistance in endometrial cancer cell line. J. Transl. Med. 2019; 17 (1):58.

15. Sanderson P.A., Critchley H.O.D., Williams A.R.W., et al. New concepts for an old problem: the diagnosis of endometrial hyperplasia. Human Reprod Update.2016; 1(2):232-54.

16. Rubisz P., Ciebiera M., Hirnle L., Zgliczynska M., Lozinski T., Dziegiel P., et al. The usefulness of immunohistochemistry in the differential diagnosis of lesions originating from the myometrium. International journal of molecular science.2019; 20:1-23.

17. Saksonk F.A., AL kadhi Y.A. Endometrial carcinoma .e. medicin/Obst \&Gyn. 2007.

18. Van Diest P.J, Brugal G., Baak J.P.A. "Proliferation markers in tumours: Interpretation and clinical value," Journal of Clinical Pathology. 1998; 51(10):716-24.

19. Juríková M., Danihel L., Polák S., Varga I., et al. "Ki67, PCNA, and MCM proteins: Markers of proliferation in the diagnosis of breast cancer," Acta Histochemica. 2016; 118(5):544-552.

20. Dzulkifli1 F.A., Mashor M.Y., Jaafar H. An overview of recent counting methods for $\mathrm{Ki} 67$
IHC staining. J. of Biomed. \& Clin. Sci. 2018; 3 (2):10-17.

21. Soliman N., Yussif Sh.M. Ki-67 as a prognostic marker according to breast cancer molecular subtype. Cancer Biology Medicine. 2016; 13(4):496-504.

22. Kitson S., Sivalingam V.N., and Bolton J., McVey R., Nickkho-Amiry M., Powell M.E., et al. Ki-67 in endometrial cancer: scoring optimization and prognostic relevance for window studies. Official journal of the United States and Canadian academy of pathology. 2017; 30:45968.

23. Al-Nuaimi H.A., Hamdi E.A.W., Mohammed B.B. Ki-67 expression in breast cancer , Its correlation with ER,PR, and other prognostic factors in Nineveh province. Annals of the college of medicine, Mosul. 2020; 42(1):1-10.

24. Vedula B., Chandrika V.L.K., Ravikumar M.S. Histopathological spectrum of endometrial changes in abnormal uterine bleeding. IOSRJDMS. 2020; 19(2):1-5.

25. Kaur P., Kaur A., Suri A.K., Sidhu H. A two year histopathological study of endometrial biopsies in a teaching hospital in Northern India. IJPO. 2016; 3(3):508-19.

26. Shan R.S., James G., Richard J., Lillian Y., Debra H., Yan S. Applied immunohistochemistry \& Molecular Morphology.1999; 7:201-9.

27. Petrosyan K., Tamayo R., Joseph D. Sensitivity of a Novel Biotin-free Detection Reagent (power vision+) for immunohistochemistry. Journal of Histotechnology. 2002; 25:247-50.

28. Zimik T., Longjam D., Devil S. A study of histopathological spectrum of endometrial lesions in abnormal uterine bleeding with analysis of expression pattern of ER, PR and KI67. Paripex Indian journal of research.2020; 9(6):1991-2250.

29. Shalini P., Suresh N., Ganapathy H. Ki - 67 Expression in Endometrial Hyperplasia. Indian Journal of Public Health Research \& Development. 2019; 10(11).

30. Gharib F., Mohamed D.A.E., Almorsy W.A. Expression of L1CAM and $\mathrm{Ki}-67$ in endometrial cancer of Egyptian females: clinical impact and survival. Tumori Journal 106 (1_suppl). 2020; 14(5):001-006.

31. Carangui M.L., Chambers J.T., Voynick I.M., Pirro M., Schwartz P.E. Immunohistochemical Evaluation of Estrogen and Progesterone Receptor content in 183 Patients with Endometrial Carcinoma. Part I: Clinical and Histologic Correlations. AM J Clin Pathol.1990; 94(3): 247-254.

32. Ahmed A.H., Al-Nuaimy W. Immunohistochemical detection of estrogen 
receptor alpha in endometrial carcinoma. Ann. Coll. Med, Mosul. 2019; 36(1\&2):7-130.

33. Bhattacharya $A B$, Jha $M$, Agarwal $A$ Histopathological and immunohistochemical study of endometrial lesions obtained from D\&C and hysterectomy specimens at a tertiary care hospital, Original article. 2018; DOI: 10.21276/APALM.1883.

34. Shevra C.R., Ghosh A., Kumar M. Cyclin D1 and Ki-67 expression in normal, hyperplastic and neoplastic endometrium. Journal of postgraduate medicine. 2015; 61(1):15-20.

35. Suthipintawaong C., Wejaranayang C., Vipupinyo C. Prognostic significance of ER, PR, Ki67, C-erbB2, and P53 in endometrial carcinoma, J. Med. Assoc. thai. 2008; 91(12):841779.

36. Sidonia S., Cristiana S., Margaritescu C.I., Stepan A., Nurciu M. Endometrial carcinomas: correlation between ER. PR, Ki67 status and histopathological prognostic parameters. Rom J Morphol Embryol. 2011; 52(2):631-6.

37. Feng $Y$. Clinical analysis in 56 cases of $p / v$ bleeding, HeBei Med. 1989; 12:78-81.

38. Yu C.G., Jiang X.Y., Li B., Gan L., Huang J. Expression of ER, PR, C erbB-2 and Ki-67 in endometrial carcinoma and their relationships with the clinicopathological features, Asian Pac J Cancer Prev. 2015;16(15):6789-94.

39. Al-Nuaimy W.M., Al-Allaf L.I., Alnaimi H.A. P53 Expression in Prostatic Cancer: An Immunohistochemical study. J Med J. 2011; 45(1).

40. Zidan A.A, Hassan A.A., Seadah S.S., Ibrahim E.H., Attiah S.M. Selected immunohistochemical prognostic factors in endometrial hyperplasia versus carcinoma. Journal of American Science. 2015; 11(4):14-22

41. Jiang P., Jia M., Hu J., Huang Z., Deng Y., Ding S., et al. Prognostic Value of Ki67 in Patients with Stage 1-2 Endometrial Cancer: Validation of the Cut-off Value of Ki67 as a Predictive Factor. OncoTargets and Therapy. 2020; 13:10841-50.

42. Hoffman B.L, Schorge J.O., Bradshaw K.D., Halvorson L.M., Schaffer J.I., et al. Williams Gynecology, fourth edition, Mc Graw- Hill Education, 2020;ISBN-13:978-1260456868.

43. Stoenescu V.E., Niculescu M., Novac L., Manolea M.M., Tomescu P.I., Dijmarescu A.,et al. Immunohistochemical reaction of the glandular epithelium in endometrial hyperplasia compared to endometrial carcinoma. Rom J Morphol Embryol. 2017; 58(3):791-800.

44. Masood S., Khadim M.T, Ali S.S. Histopathological spectrum of endometrial lesions in patients with Abnormal Uterine Bleeding. Pak J pathol. 2017; 28(1):6-12.
45. Stavropoulos A, Varras M, Vasilakaki T, Varra V., Tsavari A., Varra F.,et al. Expression of p53 and PTEN in human primary endometrial carcinomas: Clinicopathological and immunohistochemical analysis and study of their concomitant expression. Oncol Lett. 2019; 17(5):4575-4589. doi:10.3892/ol.2019.10093

46. Liu T., Gao H., Yang M., Zhao T., LIU Y., Lou G. Correlation of TNFAIP8 overexpression with the proliferation, metastasis, and disease-free survival in endometrial cancer. Tumour Biol 2014; 35:5805-14.

47. Lax S.F. Pathology of endometrial carcinoma. In: Molecular Genetics of Endometrial Carcinoma. Springer: Cham. 2017; 75-96.

48. Stelloo E., Nout R.A., Osse E.M., JurgenliemkSchulz I.J., Jobsen J.J., Lutgens L.C., et al. Improved Risk Assessment by Integrating Molecular and Clinicopathological Factors in Early-stage Endometrial Cancer-Combined Analysis of the PORTEC Cohorts. Clin Cancer Res. 2016; 22(16):24-4215. doi:10.1158/10780432.ccr-15-2878.

49. Faneyte I.F., Schrama J.G., Peterse J.L., Remijnse P.L., Rodenhuis S., Vijver M.V. Breast cancer response to neoadjuvant chemotherapy: predictive markers and relation with outcome. British Journal of Cancer. 2003;88:12406.doi:10.1038/sj.bjc.6600749 www.bjcancer.com. 